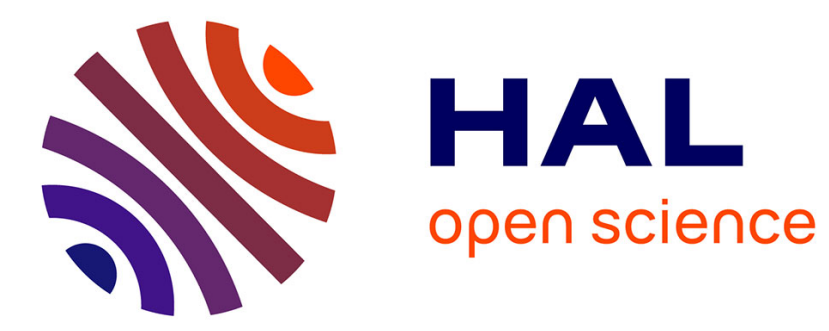

\title{
Genetics of neonatal onset epilepsies: An overview
} Mathieu Milh, Florence Riccardi, J. Denis

\section{To cite this version:}

Mathieu Milh, Florence Riccardi, J. Denis. Genetics of neonatal onset epilepsies: An overview. Revue Neurologique, 2020, 176 (1-2), pp.2-9. 10.1016/j.neurol.2019.01.396 . hal-03222897

\section{HAL Id: hal-03222897 \\ https://hal-amu.archives-ouvertes.fr/hal-03222897}

Submitted on 11 May 2021

HAL is a multi-disciplinary open access archive for the deposit and dissemination of scientific research documents, whether they are published or not. The documents may come from teaching and research institutions in France or abroad, or from public or private research centers.
L'archive ouverte pluridisciplinaire HAL, est destinée au dépôt et à la diffusion de documents scientifiques de niveau recherche, publiés ou non, émanant des établissements d'enseignement et de recherche français ou étrangers, des laboratoires publics ou privés.

\section{(이)(\$)}

Distributed under a Creative Commons Attribution - NonCommercial - NoDerivatives| 4.0 


\title{
Genetics of Neonatal Onset Epilepsies : An Overview
}

\author{
Mathieu Milh ${ }^{1,2 *}$, Florence Riccardi ${ }^{1,2}$, Julien Denis ${ }^{1,2}$ \\ ${ }^{1}$ Aix-Marseille Univ, Jardin du Pharo, 58 Boulevard Charles Livon, 13007 Marseille, \\ France \\ ${ }^{2}$ APHM ; Pediatric neurology Unit. Timone Children Hospital, 278 Rue Saint-Pierre, \\ 13005 Marseille, France
}

*Corresponding author

Mathieu Milh, Pediatric neurology Unit. Timone Children Hospital, 278 Rue Saint-

Pierre, 13005 Marseille, France

mathieu.milh@ap-hm.fr 


\begin{abstract}
The weight of monogenic abnormalities in the possible causes of epilepsy has grown significantly in recent years, due to the emergence of next-generation sequencing (NGS) techniques. Especially notable in early neonatal and infantile epilepsies, which seem to be explained by monogenic abnormalities.

This short review focuses on the major genes associated with very early-onset epilepsies, where NGS techniques are most cost-effective: early infantile epileptic encephalopathy, early myoclonic encephalopathy, and other neonatal epilepsies.

The discovery of the genetic mutation often follows several weeks or months of management, and rarely modifies it. However, clinical studies can sometimes better define medical treatment.

The genetic causes of these epilepsies are very numerous and the pathophysiological knowledge very minimal. The big challenge for the coming years is to develop more targeted treatments based on research on animal models.
\end{abstract}




\section{INTRODUCTION}

The weight of monogenic anomalies in the possible causes of epilepsy has grown significantly in recent years, due to the emergence of next-generation sequencing (NGS) techniques. Progress has been particularly notable in early neonatal and infantile epilepsies, which seem to be largely explained by monogenic abnormalities.

Most of these are severe, drug-resistant epilepsies associated with a serious neurodevelopmental disorder. The term "epileptic encephalopathy", reflecting the negative impact of seizures and electroencephalographic (EEG) abnormalities on development, has often given way to the term "developmental encephalopathy with epilepsy ", reflecting the fact that it is primarily a severe developmental disorder, of which epilepsy is a major comorbidity (figure 1).

Although most probably of genetic origin, the current techniques have not made the same progress in non-structural epilepsies that occur later, and even more in non structural partial or generalized epilepsies, probably because most of them are polygenic or even multifactorial.

Despite the continuous increase in the number of epilepsy genes, the syndromic approach remains relevant for at least two reasons: 1. The diagnosis of the epileptic syndrome remains important for the therapeutic approach (example: the treatment of West's syndrome does not depend on the gene involved); 2 . The diagnosis of the syndrome can be used to guide genetic analysis for greater yield.

In some cases, the detection of a particular genetic mutation may lead to a more targeted treatment, deemed more effective against seizures (Milh et al. 2016). It is therefore important to get the results faster, while a better knowledge concerning the description of the phenotype associated with each gene could eventually lead to implement the treatment before the final genetic diagnosis.

\section{GENETICS OF NEONATAL ONSET DEVELOPEMENTAL ENCEPHALOPTHIES WITH EPILEPSIES}

The International League Against Epilepsy (ILAE) described two age-dependent electroclinical syndromes characterized by encephalopathy which occur in the neonatal 
period (Beal, Cherian, et Moshe 2012): early myoclonic encephalopathy (EME) and Ohtahara syndrome (OS), also known as early infantile epileptic encephalopathy (EIEE) () .

Each of these syndromes are characterized by a specific clinical seizure type (tonic seizures for OS, myoclonic seizures for EME), clinical signs of encephalopathy and a suppressionburst pattern on the EEG. While age of onset, underlying etiology, associated secondary clinical seizure types, co-morbidities and aspects of immediate and long-term outcome may vary within and between each syndromic category, both EME and EIEE share some common features which contribute to the high incidence of neurological impairment in affected infants.

An important common feature in both groups is the finding of a suppression-burst pattern on EEG as part of the diagnostic criteria for both EME and EIEE (Auvin, Cilio, and Vezzani 2016). A suppression-burst pattern may be observed in a number of conditions in the neonate (Lombroso 1990). However when the pattern is associated with clinical seizures and signs of encephalopathy, the disorders of EME and EIEE are initially considered, depending upon predominant seizure type. Because the suppression-burst pattern is highly abnormal and recognizable, and because it may be due to the same pathophysiology, early onset epilepsies with a suppression-busrt pattern have been studied as a unique entity.

Although genetic factors have been most recently intensively investigated in neonatal onset epilepsies, structural brain abnormalities still represent an important etiologic factor and should not be overlooked. Metabolic disorders have been reported to occur in fewer cases, mostly with myoclonias including: nonketotic hyperglycinemia, cytochrome oxidase deficiency hyperglycinemia, D-glyceric acidemia, methylmalonic acidemia, hyperammonemia, proprionic acidemia, and urinary secretion of abnormal oligosaccharides. In addition, some cases have been reported in association with Leigh's encephalopathy (Lombroso 1990)

There has been a growing literature describing genetic mutations in EIEE without any structural brain abnormality. 
Recently, Olson et al. described the first cohort of patients with EIEE-BS without cortical malformation and identified mutations in 17 patients (61\%) (Olson et al. 2017). Based on the medical literature, mutations in 18 genes (ALG1, ALDH7A1, ARX, BRAT1, CDKL5, GABRB2, GNAO1, KCNQ2, KCNT1, PIGA, PIGQ, PNPO, SCN2A, SEPSECS, SLC25A22, SLC35A3, STXBP1, SRGAP2 and ZEB2 genes) have been identified in this subgroup of patients.

\section{$1.1 \mathrm{KCNQ} 2$}

Among those genes, $K C N Q 2$ was found mutated in approximatively a quarter of the patients and was by far the most frequent of the cohort. Weckhuysen et al. (Weckhuysen et al. 2012) screened $K C N Q 2$ and $K C N Q 3$ in a cohort of early onset epileptic encephalopathy. Surprisingly, they found a $K C N Q 2$ mutation (already known to be associated with benign familial neonatal seizures [BFNS]) in $10 \%$ of patients, more than half of them displaying features of Ohtahara syndrome. Most of the mutations occurred de novo and were all different from those observed in BFNS.

The $K C N Q 2$ gene encodes for Kv7-2, a subunit of a voltage-gated potassium channel called Im. Im is a current that plays a crucial role in the control of generation of action potentials, and in the maintenance of the resting state of neurons.

The initial features are highly stereotyped: very early onset (first week); numerous tonic asymmetric seizures with cyanosis, sometimes poorly tolerated, very little sensitivity to phenobarbital. EEG typically shows a suppressin-burst pattern. In half of cases, it can be either asynchronous between hemispheres, or with very short periods of silence. The evolution is more heterogeneous; half of patients rapidly become seizure-free but still have major neurological impairment; half of them stay epileptic, some can have epileptic spasms around six months (Mathieu Milh, Boutry-Kryza, et al. 2013). Functional analysis of several severe $K C N Q 2$ mutations have revealed that mutations could have several consequences and lead to a relatively similar phenotype: negative impact on Im (dominant negative action) (Orhan et al. 2014), positive impact on Im (gain of function) (Miceli et al. 2015; Devaux et al. 2016), or little impact, but alteration of the distribution of Im at the cell surface (Abidi et al. 2015). It is very intriguing to see that three different consequences can lead to a similar clinical presentation. It is likely that much remains to be done to better 
understand the pathophysiology of EIEEs. There is no controlled study considering the rarity of the condition, but the interest of the sodium channel blockers (SCB) deserves to be emphasized. Indeed, several teams have shown that $K C N Q 2$-related EIEEs are remarkably sensitive to carbamazepine and sodium blockers in general (Pisano et al. 2015; Abidi et al. 2015). Currently it is recommended to use SCB as soon as possible, in the hope of mitigating the deleterious effects of epilepsy. Nevertheless, it is likely that even a quick control of seizures does not allow normal development in cases of $K C N Q 2$-related neonatal epilepsies with a suppression-burst pattern.

\subsection{STXBP1}

Mutations/deletions of STXBP1 (MUNC18-1) have also been reported to be a possible etiology of EIEE (Hirotomo Saitsu et al. 2008) and is found mutated in 5 to $15 \%$ of EIEE with suppression-burst. STXBPI is a regulatory component of the SNARE complex that is placed in a late step of neuronal/exocytic fusion (H. Saitsu et al. 2012; Hirotomo Saitsu et al. 2010). The human STXBP1 gene contains 20 exons and has been mapped to 9q34.1. Exon 19 is alternatively spliced, the shorter isoform being expressed in all tissues examined and the longer isoform containing exon 19 being expressed in the brain and retina (Swanson et al. 1998). Saitsu et al. reported STXBP1 mutations in 14 unrelated patients, from a cohort of 43 patients with EIEE in two distinct papers (H. Saitsu et al. 2012; Hirotomo Saitsu et al. 2010). The patients displayed early onset seizures, typically frequent epileptic spasms, suppression-burst pattern on EEG, transition to West syndrome after a few to several months in most cases, and severe developmental delay. The authors showed that mutant STXBP1 proteins were degraded and they concluded that STXBP lhaploinsufficiency could be a major molecular marker of EIEE. Milh et al (Mathieu Milh et al. 2011,) screened this gene in 51 patients with early onset epileptic encephalopathy, of which 37 had Ohtahara syndrome. They found a mutation in five patients with Ohtahara syndrome (13\%). The epilepsy began during the first week of age for four patients, and at one month for one patient. Two patients had initially clonic seizures. During the first three months, the main type of seizure was epileptic spasms in all cases. Spasms were associated with other types of seizures: clonic seizures, tonic seizures and partial seizures. Interestingly, the five patients became seizure free during the second 
half of the first year of life. Initial EEG was discontinuous in two cases, before showing a suppression burst (SB) pattern. SB pattern was recorded from the beginning in the three remaining cases. Then, EEG turned to be more and more continuous. At six months, activity was made of generalized and asynchronous spikes and slow wave. Surprisingly, paroxysmal activity disappeared in each case before the age of one year, giving place to a continuous activity with occurrence of fast rhythms in the posterior regions. All patients had frequent dyskinetic non-epileptic movements that still persisted after epilepsy remission. More rarely, STXBP1 may be found mutated in other epileptic syndromes (West syndrome) and in several developmental encephalopathies with epilepsy that do not fit with any recognized syndrome (Di Meglio et al. 2016, Stamberger H et al. 2016). Overall, approximatively one-third of patients carrying a mutation in STXBP1 display EIEE. STXBP1 has also been implicated in other early onset epilepsies that either do not fit with any recognizable syndrome, or can be classified as early onset epileptic spasms (Deprez et al. 2010; Stamberger et al. 2016). The relationship between STXBP1 mutations and neonatal epilspies remains unclear. Recently, Devaux et al. showed that haploinsufficiency of STXBP1 could have negative impact on Im, mimicking some $K C N Q 2$ mutations. Intererstingly, epileptic and EEG features of $K C N Q 2$ and $S T X B P 1$ related epilepsies are relatively similar regarding age of onset, EEG pattern, seizure evolution and development.

\subsection{SCN2A}

The gene SCN2A encodes the voltage-gated sodium channel Nav1.2, one of the major brain sodium channels playing a pivotal role in initiation and conduction of action potentials. Nav1.2 is expressed in axon initial segments (AIS) and nodes of Ranvier of myelinated nerve fibers in early development, and in the adult brain in the AIS and unmyelinated axons. In the cohort of Olson et al. SCN2A was the second gene of EEP-SB. In a recent international study, Wolff et al. described two main phenotypes associated with SCN2A mutations: a first one represented by early onset epileptic encephalopathy beginning before three months of age (Ohtahara syndrome, Epilepsy of infancy with migrating focal seizures or non syndromic developmental encephalopathies) and a second one begining after three mojnths of age (West syndrome, Lennox-Gastaut syndrome, myoclonic-atonic epilepsies, 
focal epilepsies with centro-temporal spikes and developmental delay). They also found that sodium channel blockers (SCBs) were often associated with clinically relevant seizure reduction or seizure freedom in children with neonatal/early infantile onset epilepsies $(<3$ months), including severe forms, whereas other AEDS were less effective (Wolff et al. 2017). In contrast, response in epileptic encephalopathies with later onset ( $\geq 3$ months) was markedly poorer, including seizure worsening. Additional symptoms are more often found in SCN2A related epilepsy than in KCNQ2 or STXBP1 related epilepsies: hypotonia, microcephaly, marked choreo-athetosic movements, spasticity... Two other phenotypes have been more rarely described: autistic spectrum disorder and intellectual disability without epilepsy (approximatively 20\%), and benign neonatal/infantile onset epilepsies (15\% of cases).

\subsection{Other genes}

\subsubsection{ARX}

Mutations in aristaless-related homeobox gene $(A R X)$ may also be associated with EIEE. $A R X$ is located in the human chromosome Xp21.3 region and provides instructions for producing a protein transcription factor which is essential for the development of cerebral interneurons. A hemizygous 33-bp duplication in exon 2 was firstly described in two unrelated patients with Ohtahara syndrome (Kato et al. 2007). The infant had early onset of brief tonic seizures beginning during the first weeks of life followed by a transition from EIEE to West syndrome and severe developmental delay. Recently, Giordano et al (Giordano et al. 2010) reported the finding of the same missense mutation in the exon 5 of $A R X$ in monozygotic twin sisters with EIEE and Fullston et al. reported a family with $A R X$ protein truncation mutation (Fullston et al. 2010).

\subsubsection{SLC25A22}

Mutations in the SLC25A22 gene encoding a mitochondrial glutamate carrier were identified in two families with a neonatal encephalopathy with suppression-burst (Molinari et al. 2005 ; Goubert et al. 2017). This gene is located in the inner mitochondrial membrane and catalyzes a glutamate/H+ transport into the mitochondria. Patients presented some epileptic spasms and focal seizures from the first few days of life, with acquired 
microcephaly, severe hypotonia and a lack of any psychomotor development. EEG showed a persistent suppression-burst. Both patients had abnormal ERG recording. Brain MRI showed cerebellar hypoplasia, callosal dysmorphia and abnormal gyration of temporoparietal regions. Analysis of glutamate transport of the mutated proteins showed that glutamate could not enter into the patients mitochondria. This could result in the accumulation of glutamate in the astrocytes and lead to a dysregulation of glutamate homeostasis and neurotransmission.

\subsubsection{Genes of pyridoxine metabolism}

Vitamin B6 (pyridoxine) is involved in many biochemical reactions including the transformation of glutamate into GABA. Pyridoxine phosphate and pyridoxamine phosphate are metabolized to an active cofactor, pyridoxal phosphate (PLP). Neonatal epileptic seizures are related to:

- lack of PLP synthesis (PNPO deficiency) or - accumulation of metabolites that inactivate PLP (ALDH7A1 deficiency).

The diagnosis is based on the effectiveness of treatment with vitamin B6 (pyridoxinesensitive convulsions) or with pyridoxal phosphate (pyridoxal-phosphate-sensitive convulsions), the dosage of pipecolic acid in plasma and CSF (before treatment by B6), the determination of alpha-AASA in the urine (even if the patient is treated with B6) and homocysteinemia.

It is also possible to identify a pathogenic variation in the PNPO and $A L D H 7 A 1$ genes (Plecko 2013) using NGS techniques in cases of early onset epileptic encephalopathies (Plecko 2013)

\subsection{Abnormal protein glycosiltaion (CDG syndrome)}

Congenital protein glycosylation abnormality can be found in some patients having a suppression-bust pattern. A systematic investigation of transferine glycosilation may be proposed in patients with an early onset epileptic encephalopathy (Olson et al. 2017)

Overall, among the genes associated with EIEEs and EMEs, three seem to play a major role and represent half of the cases : $K C N Q 2, S T X B P 1$ and $S C N 2 A$. It is very difficult to 
determine a specific phenotype of one of these three genes. They usually share some characteristics: usual absence of anomaly of the measurements at birth, an EEG often showing a suppression-burst pattern, a stormy onset, with very frequent seizures from the start. Seizures often have an asymmetric tonic component and may be poorly tolerated on the respiratory level.

To date, 18 different genes have been associated with early-onset epileptic encephalopathies with a suppression-burst pattern (figure 2)

\section{OTHER NEONATAL-INFANTILE ONSET DEVELOPMENTAL ENCEPHALOPATHIES WITH EPILEPSY}

Many severe and early epilepsies do not fit with a known epileptic syndrome. These epilepsies are difficult to categorize, with frequent seizures, often diffuse EEG abnormalities and severe encephalopathy, but without a specific EEG pattern or seizure type. Again, many genes have been described. For most of them, the phenotype is heterogeneous. Some genes are more frequently found mutated:

\subsection{SCN8A}

The first report of SCN8A-related epilepsy was published in 2012.(Veeramah et al. 2012) Since then more than 100 cases have been published, most of them having early-onset epileptic encephalopathy (EOEE) typically beginning before six months of age, with high rate of sudden unexpected death (SUDEP) (Larsen et al. 2015; Veeramah et al. 2012; Wagnon et Meisler 2015)

In a French cohort of 19 patients carrying a $S C N 8 A$ pathogenic variant, we confirm that $S C N 8 A$-related epilepsy is heterogeneous. However, focusing on the very first symptoms, first examination and first EEG of our 19 patients, we were able to identify two orthogonal modes of onset regarding the delay between first seizure or event and diagnosis of EE, but also regarding seizure type or frequency and interictal EEG. One mode of onset was typically observed and described in EE, with sudden onset of seizures (mostly tonic seizures and epileptic spasms), abnormal interictal EEG leading to rapid diagnosis of EE and abnormal development. This type of onset has been described for the majority of genetic mutations associated with neonatal onset epileptic encephalopathies. The other mode of onset is more insidious since the first months are relatively calm in terms of 
epileptic activity, either with recurrent GTCS with normal development and EEG, or with myoclonic jerks, jitteriness or tremor that could eventually be mistaken for normal movements. This mode of onset was predominant in our cohort, although it seems to be less frequently observed in the literature. Interestingly, the majority of patients carrying a mutation of SCN8A were sensitive to sodium channel blockers, such as carbamazepine and phenytoin. We saw that the location of mutation within the gene could predict relatively well the response to sodium channel blockers.

\section{$2.2 \mathrm{KCNT} 1$}

KCNT1 has been first found mutated in patients having an epileptic syndrome of early infancy, so-called Epilepsy of infancy with migrating focal seizures (EIMFS) (Barcia et al. 2012). It is a rare age-related epileptic and developmental encephalopathy, initially described in 1995. The key features of EIMFS include focal seizures in the first six months of life, acquired microcephaly, a progressive developmental delay and a specific EEG ictal pattern called "migrating seizure", included in the name of this syndrome. Migrating seizures are described as overlapping and multifocal ictal activities, shifting from one cerebral region or hemisphere to another.

In numerous cases, $K C N T 1$ is not associated with EIMFS, but with others early onset severe epilepsies.

Since $K C N T 1$ mutations are gain of function mutations, quinidine has been identified as a possible personalized treatment in this condition. Functional studies have actually shown that quinidine could restore a normal function of mutated KCNT1. However, the efficacy of quinidine in vitro is controversial. Some authors reported a dramatic efficacy on seizure frequency will others did not report any clinical response (Abdelnour et al. 2018; Mullen et al. 2018; Dilena et al. 2018; Mikati et al. 2015).

\section{$2.3 \mathrm{TBC} 1 \mathrm{D} 24$}

Biallelic mutations of TBC1D24 were initially described in familial myoclonus epilepsies. Subsequently, this gene has been implicated in various epilepsies, in particular epilepsy with migrating spartial seizures, and a complex developmental disorder: the DOORS syndrome, associating deafness, ophthalmological impairment, assertiveness, intellectual disability and seizures epilepsy. The phenotype associated with this gene is highly variable 
in severity, but most patients have very prolonged myoclonic seizures (Balestrini et al. 2016; Campeau et al. 2014; Mathieu Milh, Falace, et al. 2013; Falace et al. 2010)

\section{CONCLUSION}

Genetics occupy a very important place in the etiological workup of early onset epileptic and/or developmental encephalopathies. The genotype / phenotype correlations are difficult and unspecific, so that most teams currently propose to study not one but dozens of genes involved in monogenic epilepsies in one shot, in such a condition. These panels contain at least a hundred genes that have been reported several times in the literature as implicated in early and severe epilepsies. The clinician still plays a major role by indicating this type of analysis to the right candidates, by clinically validating the mutations found and by explaining the results to the patients and families.

Because KCNQ2, SCN2A and SCN8A are frequently found mutated in neonatal onset epileptic encephalopathies, and because sodium channel blockers (SCB) have been found to be possibly effective in these conditions, SCB may be rapidly used in case of early onset epilepsy without any occasional cause and with non-structural brain MRI. It is especially true in case of an early-onset epileptic encephalopathy with a suppression-burst pattern, where $K C N Q 2$ and $S C N 2 A$ mutations may be find in nearly half of the patients. Moreover, aggravation of epilepsy by SCB seems to be very infrequent when epilepsy begins during the neonatal period, in contrast to what has been described in West syndrome or LennoxGastaut syndrome.

In 2018, despite advances in sequencing techniques, nearly $30 \%$ of patients remain without diagnosis, and no true physiological-based targeted therapy exists: some work still has to be done. 
Abdelnour, Elie, William Gallentine, Marie McDonald, Monisha Sachdev, Yong-Hui Jiang, et Mohamad A. Mikati. 2018. «Does Age Affect Response to Quinidine in Patients with KCNT1 Mutations? Report of Three New Cases and Review of the Literature $» . \quad$ Seizure $\quad 55 \quad$ (février): https://doi.org/10.1016/j.seizure.2017.11.017.

Abidi, Affef, Jérôme J. Devaux, Florence Molinari, Gisèle Alcaraz, François-Xavier Michon, Julie Sutera-Sardo, Hélène Becq, et al. 2015. « A Recurrent KCNQ2 Pore Mutation Causing Early Onset Epileptic Encephalopathy Has a Moderate Effect on M Current but Alters Subcellular Localization of Kv7 Channels ». Neurobiology of Disease 80 (août): 80-92. https://doi.org/10.1016/j.nbd.2015.04.017.

Auvin, Stéphane, Maria Roberta Cilio, et Annamaria Vezzani. 2016. «Current Understanding and Neurobiology of Epileptic Encephalopathies ». Neurobiology of Disease 92 (Pt A): 72-89. https://doi.org/10.1016/j.nbd.2016.03.007.

Balestrini, Simona, Mathieu Milh, Claudia Castiglioni, Kevin Lüthy, Mattea J. Finelli, Patrik Verstreken, Aaron Cardon, et al. 2016. «TBC1D24 Genotype-Phenotype Correlation: Epilepsies and Other Neurologic Features ». Neurology 87 (1): 77-85. https://doi.org/10.1212/WNL.0000000000002807.

Barcia, Giulia, Matthew R. Fleming, Aline Deligniere, Valeswara-Rao Gazula, Maile R. Brown, Maeva Langouet, Haijun Chen, et al. 2012. «De Novo Gain-of-Function KCNT1 Channel Mutations Cause Malignant Migrating Partial Seizures of Infancy ». Nature Genetics 44 (11): 1255-59. https://doi.org/10.1038/ng.2441.

Beal, Jules C., Koshi Cherian, et Solomon L. Moshe. 2012. «Early-Onset Epileptic Encephalopathies: Ohtahara Syndrome and Early Myoclonic Encephalopathy ». $\begin{array}{lllll}\text { Pediatric } & \text { Neurology } & 47 & \text { (5): }\end{array}$ https://doi.org/10.1016/j.pediatrneurol.2012.06.002.

Campeau, Philippe M., Dalia Kasperaviciute, James T. Lu, Lindsay C. Burrage, Choel Kim, Mutsuki Hori, Berkley R. Powell, et al. 2014. « The Genetic Basis of DOORS 
Syndrome: An Exome-Sequencing Study ». The Lancet. Neurology 13 (1): 44-58. https://doi.org/10.1016/S1474-4422(13)70265-5.

Deprez, L., S. Weckhuysen, P. Holmgren, A. Suls, T. Van Dyck, D. Goossens, J. DelFavero, et al. 2010. «Clinical Spectrum of Early-Onset Epileptic Encephalopathies Associated with STXBP1 Mutations ». Neurology 75 (13): 1159-65. https://doi.org/10.1212/WNL.0b013e3181f4d7bf.

Devaux, Jérôme, Affef Abidi, Agathe Roubertie, Florence Molinari, Hélène Becq, Caroline Lacoste, Laurent Villard, Mathieu Milh, et Laurent Aniksztejn. 2016. «A Kv7.2 Mutation Associated with Early Onset Epileptic Encephalopathy with SuppressionBurst Enhances Kv7/M Channel Activity». Epilepsia 57 (5): e87-93. https://doi.org/10.1111/epi.13366.

Dilena, Robertino, Jacopo C. DiFrancesco, Maria Virginia Soldovieri, Antonella Giacobbe, Paolo Ambrosino, Ilaria Mosca, Maria Albina Galli, et al. 2018. « Early Treatment with Quinidine in 2 Patients with Epilepsy of Infancy with Migrating Focal Seizures (EIMFS) Due to Gain-of-Function KCNT1 Mutations: Functional Studies, Clinical Responses, and Critical Issues for Personalized Therapy ». Neurotherapeutics: The Journal of the American Society for Experimental NeuroTherapeutics, août. https://doi.org/10.1007/s13311-018-0657-9.

Falace, Antonio, Fabia Filipello, Veronica La Padula, Nicola Vanni, Francesca Madia, Davide De Pietri Tonelli, Fabrizio A. de Falco, et al. 2010. « TBC1D24, an ARF6Interacting Protein, Is Mutated in Familial Infantile Myoclonic Epilepsy». American Journal of Human Genetics 87 (3): 365-70. https://doi.org/10.1016/j.ajhg.2010.07.020.

Fullston, Tod, Louise Brueton, Tracey Willis, Sunny Philip, Lesley MacPherson, Merran Finnis, Jozef Gecz, et Jenny Morton. 2010. «Ohtahara Syndrome in a Family with an ARX Protein Truncation Mutation (c.81C >G/p.Y27X)». European Journal of Human Genetics: EJHG 18 (2): 157-62. https://doi.org/10.1038/ejhg.2009.139.

Giordano, L., S. Sartori, S. Russo, P. Accorsi, J. Galli, A. Tiberti, E. Bettella, et al. 2010. «Familial Ohtahara Syndrome due to a Novel ARX Gene Mutation ». American Journal of Medical Genetics. Part A 152A (12): 3133-37. https://doi.org/10.1002/ajmg.a.33701. 
Goubert, Emmanuelle, Yanina Mircheva, Francesco M. Lasorsa, Christophe Melon, Emanuela Profilo, Julie Sutera, Hélène Becq, et al. 2017. «Inhibition of the Mitochondrial Glutamate Carrier SLC25A22 in Astrocytes Leads to Intracellular Glutamate Accumulation». Frontiers in Cellular Neuroscience 11: 149. https://doi.org/10.3389/fncel.2017.00149.

Kato, Mitsuhiro, Shinji Saitoh, Atsushi Kamei, Hideaki Shiraishi, Yuki Ueda, Manami Akasaka, Jun Tohyama, Noriyuki Akasaka, et Kiyoshi Hayasaka. 2007. « A Longer Polyalanine Expansion Mutation in the ARX Gene Causes Early Infantile Epileptic Encephalopathy with Suppression-Burst Pattern (Ohtahara Syndrome) ». American Journal of Human Genetics 81 (2): 361-66. https://doi.org/10.1086/518903.

Larsen, Jan, Gemma L. Carvill, Elena Gardella, Gerhard Kluger, Gudrun Schmiedel, Nina Barisic, Christel Depienne, et al. 2015. «The phenotypic spectrum of SCN8A $\begin{array}{lllll}\text { encephalopathy } » & \text { Neurology } & 84 & \text { (5): } & \text { 480-89. }\end{array}$ https://doi.org/10.1212/WNL.0000000000001211.

Lombroso, C. T. 1990. «Early Myoclonic Encephalopathy, Early Infantile Epileptic Encephalopathy, and Benign and Severe Infantile Myoclonic Epilepsies: A Critical Review and Personal Contributions ». Journal of Clinical Neurophysiology: Official Publication of the American Electroencephalographic Society 7 (3): 380-408.

Miceli, Francesco, Maria Virginia Soldovieri, Paolo Ambrosino, Michela De Maria, Michele Migliore, Rosanna Migliore, et Maurizio Taglialatela. 2015. « Early-Onset Epileptic Encephalopathy Caused by Gain-of-Function Mutations in the Voltage Sensor of Kv7.2 and Kv7.3 Potassium Channel Subunits ». The Journal of Neuroscience: The Official Journal of the Society for Neuroscience 35 (9): 3782-93. https://doi.org/10.1523/JNEUROSCI.4423-14.2015.

Mikati, Mohamad A., Yong-Hui Jiang, Michael Carboni, Vandana Shashi, Slave Petrovski, Rebecca Spillmann, Carol J. Milligan, et al. 2015. «Quinidine in the Treatment of KCNT1-Positive Epilepsies ». Annals of Neurology 78 (6): 995-99. https://doi.org/10.1002/ana.24520. 
Milh, M., P. Cacciagli, C. Ravix, C. Badens, A. Lépine, N. Villeneuve, et L. Villard. 2016. «Severe Neonatal Seizures: From Molecular Diagnosis to Precision Therapy?» Revue Neurologique 172 (3): 171-73. https://doi.org/10.1016/j.neurol.2016.02.005.

Milh, Mathieu, Nadia Boutry-Kryza, Julie Sutera-Sardo, Cyril Mignot, Stéphane Auvin, Caroline Lacoste, Nathalie Villeneuve, et al. 2013. « Similar early characteristics but variable neurological outcome of patients with a de novo mutation of KCNQ2 ». Orphanet journal of rare diseases 8 (1): 80.

Milh, Mathieu, Antonio Falace, Nathalie Villeneuve, Nicola Vanni, Pierre Cacciagli, Stefania Assereto, Rima Nabbout, et al. 2013. «Novel compound heterozygous mutations in TBC1D24 cause familial malignant migrating partial seizures of infancy ». Human mutation 34 (6): 869-872.

Milh, Mathieu, Nathalie Villeneuve, Mondher Chouchane, Anna Kaminska, Cécile Laroche, Marie Anne Barthez, Cyril Gitiaux, et al. 2011. «Epileptic and nonepileptic features in patients with early onset epileptic encephalopathy and STXBP1 mutations ». Epilepsia 52 (10): 1828-1834.

Molinari, Florence, Annick Raas-Rothschild, Marlene Rio, Giuseppe Fiermonte, Ferechte Encha-Razavi, Luigi Palmieri, Ferdinando Palmieri, et al. 2005. «Impaired Mitochondrial Glutamate Transport in Autosomal Recessive Neonatal Myoclonic Epilepsy». American Journal of Human Genetics 76 (2): 334-39. https://doi.org/10.1086/427564.

Mullen, Saul A., Patrick W. Carney, Annie Roten, Michael Ching, Paul A. Lightfoot, Leonid Churilov, Umesh Nair, et al. 2018. «Precision Therapy for Epilepsy due to KCNT1 Mutations: A Randomized Trial of Oral Quinidine ». Neurology 90 (1): e67-72. https://doi.org/10.1212/WNL.0000000000004769.

Olson, Heather E., McKenna Kelly, Christopher M. LaCoursiere, Rebecca Pinsky, Dimira Tambunan, Catherine Shain, Sriram Ramgopal, et al. 2017. «Genetics and Genotype-Phenotype Correlations in Early Onset Epileptic Encephalopathy with Burst Suppression». Annals of Neurology $81 \quad$ (3): 419-29. https://doi.org/10.1002/ana.24883.

Orhan, Gökce, Merle Bock, Dorien Schepers, Elena I. Ilina, Stephanie Nadine Reichel, Heidi Löffler, Nicole Jezutkovic, et al. 2014. «Dominant-Negative Effects of 
KCNQ2 Mutations Are Associated with Epileptic Encephalopathy ». Annals of Neurology 75 (3): 382-94. https://doi.org/10.1002/ana.24080.

Pisano, Tiziana, Adam L. Numis, Sinéad B. Heavin, Sarah Weckhuysen, Marco Angriman, Arvid Suls, Barbara Podesta, et al. 2015. «Early and Effective Treatment of KCNQ2 Encephalopathy $\gg$ Epilepsia $56 \quad$ (5): 685-91. https://doi.org/10.1111/epi.12984.

Plecko, Barbara. 2013. «Pyridoxine and Pyridoxalphosphate-Dependent Epilepsies ». Handbook of Clinical Neurology 113: 1811-17. https://doi.org/10.1016/B978-0444-59565-2.00050-2.

Saitsu, H., M. Kato, M. Shimono, A. Senju, S. Tanabe, T. Kimura, K. Nishiyama, et al. 2012. «Association of Genomic Deletions in the STXBP1 Gene with Ohtahara Syndrome ». Clinical Genetics 81 (4): 399-402. https://doi.org/10.1111/j.13990004.2011.01733.x.

Saitsu, Hirotomo, Mitsuhiro Kato, Takeshi Mizuguchi, Keisuke Hamada, Hitoshi Osaka, Jun Tohyama, Katsuhisa Uruno, et al. 2008. «De Novo Mutations in the Gene Encoding STXBP1 (MUNC18-1) Cause Early Infantile Epileptic Encephalopathy ». Nature Genetics 40 (6): 782-88. https://doi.org/10.1038/ng.150.

Saitsu, Hirotomo, Mitsuhiro Kato, Ippei Okada, Kenji E. Orii, Tsukasa Higuchi, Hideki Hoshino, Masaya Kubota, et al. 2010. «STXBP1 Mutations in Early Infantile Epileptic Encephalopathy with Suppression-Burst Pattern ». Epilepsia 51 (12): 2397-2405. https://doi.org/10.1111/j.1528-1167.2010.02728.x.

Stamberger, Hannah, Marina Nikanorova, Marjolein H. Willemsen, Patrizia Accorsi, Marco Angriman, Hartmut Baier, Ira Benkel-Herrenbrueck, et al. 2016. « STXBP1 Encephalopathy: A Neurodevelopmental Disorder Including Epilepsy». Neurology 86 (10): 954-62. https://doi.org/10.1212/WNL.0000000000002457.

Veeramah, Krishna R., Janelle E. O’Brien, Miriam H. Meisler, Xiaoyang Cheng, Sulayman D. Dib-Hajj, Stephen G. Waxman, Dinesh Talwar, et al. 2012. « De Novo Pathogenic SCN8A Mutation Identified by Whole-Genome Sequencing of a Family Quartet Affected by Infantile Epileptic Encephalopathy and SUDEP». American Journal of Human Genetics 90 (3): 502-10. https://doi.org/10.1016/j.ajhg.2012.01.006. 
Wagnon, Jacy L., et Miriam H. Meisler. 2015. «Recurrent and Non-Recurrent Mutations of SCN8A in Epileptic Encephalopathy ». Frontiers in Neurology 6 (mai). https://doi.org/10.3389/fneur.2015.00104.

Weckhuysen, Sarah, Simone Mandelstam, Arvid Suls, Dominique Audenaert, Tine Deconinck, Lieve R. F. Claes, Liesbet Deprez, et al. 2012. «KCNQ2 Encephalopathy: Emerging Phenotype of a Neonatal Epileptic Encephalopathy ». Annals of Neurology 71 (1): 15-25. https://doi.org/10.1002/ana.22644.

Wolff, Markus, Katrine M. Johannesen, Ulrike B. S. Hedrich, Silvia Masnada, Guido Rubboli, Elena Gardella, Gaetan Lesca, et al. 2017. «Genetic and Phenotypic Heterogeneity Suggest Therapeutic Implications in SCN2A-Related Disorders ». $\begin{array}{llllll}\text { Brain: A Journal of Neurology } 140 & \text { (5): }\end{array}$ https://doi.org/10.1093/brain/awx054. 
Figure 1. Representative EEGs of patients with an early onset epileptic encephalopathy and a suppression-burst pattern. Patient of 7 days with a KCNQ2 related epileptic encephalopathy (top), patient of 5 days with a KCNQ2 related epileptic encephalopathy (middle) and patient of 13 days with a STXBP1-relate EE.

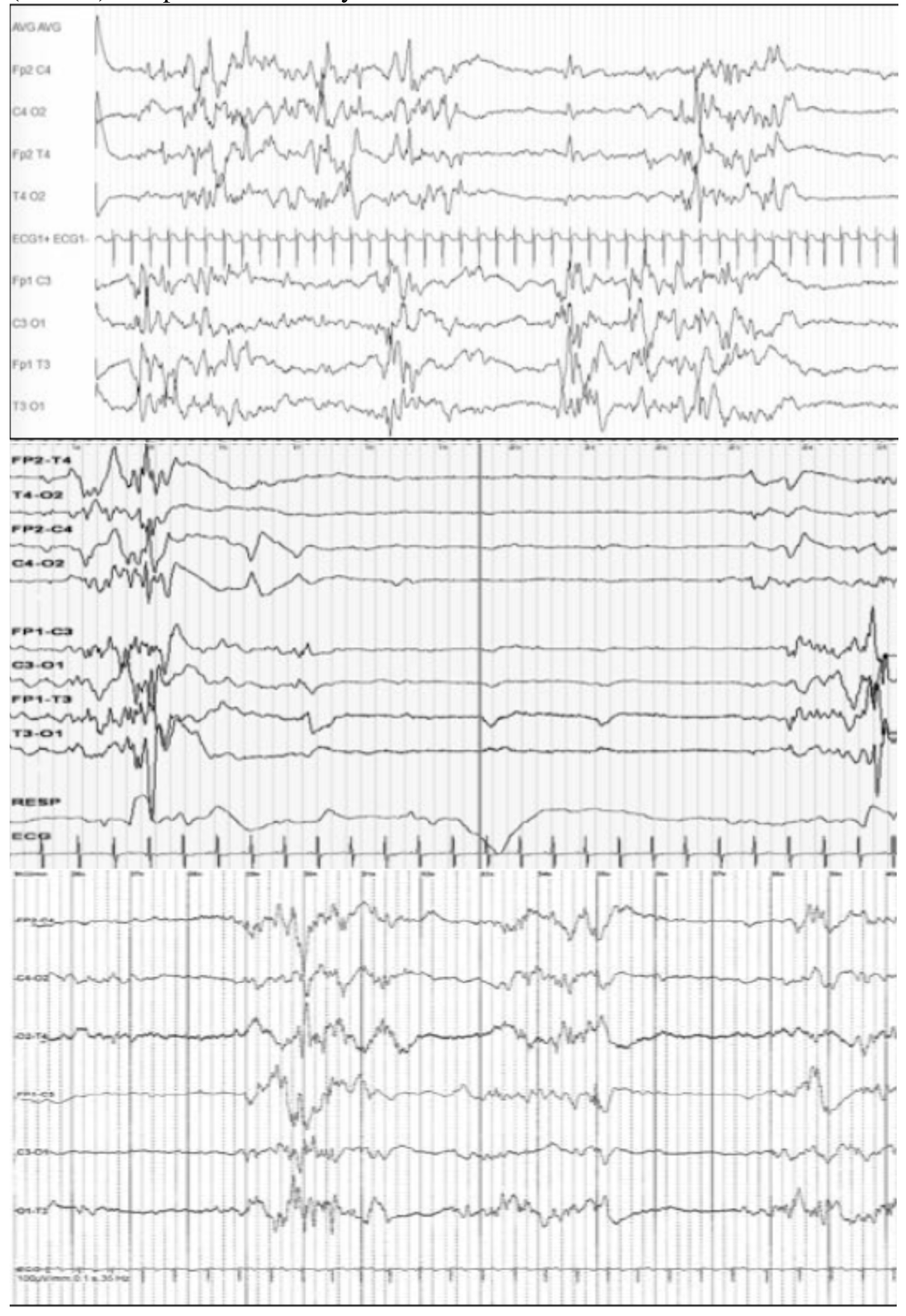




\begin{tabular}{|c|c|c|c|c|c|}
\hline $\begin{array}{c}C D K L 5 \\
\left({ }^{*} 300203\right)\end{array}$ & Xp22.13 & XLD & $\begin{array}{c}\text { Cyclin-dependent Serine/Threonine kinase: } \\
\text { auphosphorylation and phosphorylation of various } \\
\text { proteins as MeCP2 and splicing regularoty. Crucial } \\
\text { roles in cerebral development (neuronal } \\
\text { maturation and synaptogenesis) }\end{array}$ & Melani et al. (2011) & 2 \\
\hline $\begin{array}{l}\text { SLC25A22 } \\
\left({ }^{*} 609302\right)\end{array}$ & $11 \mathrm{p} 15.5$ & AR & $\begin{array}{c}\text { Mitochondrial glutamate/H+ symporters: } \\
\text { transport glutamate and } \mathrm{H}+\text { moleculares across } \\
\text { the inner mitochondrial membrane }\end{array}$ & $\begin{array}{l}\text { Molinari et al. (2005), } \\
\text { Molinari et al. (2009) }\end{array}$ & 2 \\
\hline $\begin{array}{c}\text { GNAO1 } \\
\left({ }^{*} 139311\right)\end{array}$ & $16 q 12.2$ & de novo & $\begin{array}{l}\text { Guanine nucleotide-binding protein (G protein) } \\
\text { alpha subunit type "other": hydrolyzation of } \\
\text { GTP and interaction with specific receptor and } \\
\text { effector molecules (signal-transducing molecules) }\end{array}$ & Gerald et al. (2018) & 1 \\
\hline $\begin{array}{c}A L G 1 \\
\left({ }^{*} 605907\right)\end{array}$ & $16 p 13.3$ & $A R$ & $\begin{array}{c}\text { Mannosyltransferase: biosynthesis of lipid-linked } \\
\text { oligosaccharide side chain at the outer leaflet of } \\
\text { the endoplasmic reticulum (first step) }\end{array}$ & Fiumara et al. 2015 & 1 \\
\hline $\begin{array}{c}\text { ZEB2 } \\
\left({ }^{*} 605802\right)\end{array}$ & $2 q 22.3$ & $A D$ & $\begin{array}{c}\text { Zinc finger homeobox: DNA binding } \\
\text { transcriptional repressor. }\end{array}$ & Babkina et al. (2016) & 1 \\
\hline $\begin{array}{r}\text { GABRB2 } \\
\left({ }^{*} 600232\right)\end{array}$ & $5 q 34$ & $A D$ & $\begin{array}{l}\text { Gamma-aminobutyric acid (GABA) -A receptor: } \\
\text { ligand-gated chloride channels through which the } \\
\text { GABA acts. }\end{array}$ & Ishii et al. (2017) & 1 \\
\hline $\begin{array}{l}\text { SEPSECS } \\
\left({ }^{*} 613009\right)\end{array}$ & $4 p 15.2$ & $A R$ & $\begin{array}{c}\text { O-Phosphoserine tRNA-Selenocysteine tRNA } \\
\text { synthase: catalyzes the final step of } \\
\text { selenocysteine synthesis }\end{array}$ & Olson et al. (2017) & 1 \\
\hline $\begin{array}{r}S L C 35 A 3 \\
\left({ }^{*} 605632\right)\end{array}$ & $1 \mathrm{p} 21.2$ & AR & $\begin{array}{c}\text { UDP-N-Acetyl-glucosamine (GIcNAc) } \\
\text { transporter: transport of UDP-GIcNAc from its } \\
\text { site of synthesis in the cytosol to its site of use in } \\
\text { the Golgi }\end{array}$ & Marini et al. (2017) & 1 \\
\hline $\begin{array}{r}\text { SRGAP2 } \\
\left({ }^{*} 606524\right)\end{array}$ & $1 q 32.1$ & $U$ & $\begin{array}{l}\text { SLIT-ROBO RHO GTPase-Activating protein: } \\
\text { role in cortical development as a regulator of } \\
\text { neuronal miaration and differentiation }\end{array}$ & Saitsu et al. (2012) & 1 \\
\hline $\begin{array}{c}K C N Q 2 \\
\left({ }^{*} 602235\right)\end{array}$ & $20 q 13.33$ & $\begin{array}{l}\text { de novo; AD } \\
\text { (mosaic } \\
\text { parent) }\end{array}$ & $\begin{array}{c}\text { M channel: slow activation and deactivation of } \\
\text { potassium conductance in neurons (M current). } \\
\text { Critical role in the neurons excitability and synaptic } \\
\text { inputs }\end{array}$ & $\begin{array}{l}\text { Dedek et al. (2003); } \\
\text { Weckhuysen et al. } \\
\text { (2012) }\end{array}$ & 47 \\
\hline $\begin{array}{c}P N P O \\
\left({ }^{*} 603287\right)\end{array}$ & $17 q 21.32$ & AR & $\begin{array}{c}\text { Pyridoxamine-phosphate oxidase: vitamin B6 } \\
\text { synthesis. Vitamine B6 has critical roles in normal } \\
\text { cellular functions including }\end{array}$ & Mills et al. (2005) & 24 \\
\hline $\begin{array}{c}\text { STXBP1 } \\
\left({ }^{*} 602926\right)\end{array}$ & $9 q 34.11$ & \begin{tabular}{|c|} 
de novo; $\mathrm{AD}$ \\
(mosaic \\
parent)
\end{tabular} & $\begin{array}{l}\text { Syntaxin-binding protein: regulation of synaptic } \\
\text { vesicle docking and fusion in neurons }\end{array}$ & Saitsu et al. (2008) & 19 \\
\hline $\begin{array}{c}\text { SCN2A } \\
\left({ }^{*} 182390\right)\end{array}$ & $2 \mathrm{q} 24.3$ & de novo & $\begin{array}{l}\text { Voltage-sensitive sodium channel: generation } \\
\text { and propagation of action potentials in neurons }\end{array}$ & Ogiwara et al. (2009) & 16 \\
\hline $\begin{array}{c}\text { BRAT1 } \\
\left({ }^{*} 614506\right)\end{array}$ & $7 p 22.3$ & AR & $\begin{array}{l}\text { BRCA1-associated ATM activator: response to } \\
\text { DNA damages } \\
\text { (interaction with BRCA1 and ATM1 (master } \\
\text { controller of the cycle signaling pathway)) }\end{array}$ & Saitsu et al. (2014) & 9 \\
\hline $\begin{array}{c}P I G A \\
\left({ }^{*} 311770\right)\end{array}$ & Xp22.2 & XLR & $\begin{array}{l}\text { Phosphatidylinositol glycan (GPI) anchor } \\
\text { biosynthesis protein (class A): biosynthesis of } \\
\text { GPI anchor (first step) } \\
\text { cell surface }\end{array}$ & Kato et al. (2014) & 5 \\
\hline $\begin{array}{l}\text { ALDH7A1 } \\
\left({ }^{*} 107323\right)\end{array}$ & $5 q 23.2$ & AR & $\begin{array}{c}\text { Alpha-aminoadipic semialdehyde } \\
\text { dehydrogenase: role in pipecolic acid pathway of } \\
\text { lysine catabolism. }\end{array}$ & Mills et al. (2010) & 5 \\
\hline $\begin{array}{c}A R X \\
(* 300382)\end{array}$ & Xp21.3 & XLR & $\begin{array}{c}\text { Aristaless-related homeobox protein } \\
\text { (transcription factor): regulation of multiple } \\
\text { transcription factor and genes involved in cell } \\
\text { migration, axonal guidance and neurogenesis. } \\
\text { Crucial roles in cerebral development }\end{array}$ & Kato et al. (2007) & 3 \\
\hline $\begin{array}{c}\text { KCNT1 } \\
\left({ }^{*} 608167\right)\end{array}$ & $9 q 34.3$ & de novo & $\begin{array}{c}\text { Sodium-activated potassium channel: slow } \\
\text { hyperpolarization that follows repetitive firing in } \\
\text { neurons }\end{array}$ & McTague et a. (2013) & 2 \\
\hline
\end{tabular}

Figure 2 : genes that have already been associated with early onset epileptic encephalopathies with a suppression-burst. Gene name/Locus/transmission mode/Function/reference/Number of published cases. Colored lines : treatable conditions. 